論文

질량분사가 있는 채널 내부 난류 유동의 외부교란에 대한 주파수 특성

나 양*, 이창진**

\title{
Frequency Response of Turbulent Flow to Momentum Forcing in a Channel with Wall Blowing
}

Yang $\mathrm{Na}^{*}$ and Changjin Lee**

\begin{abstract}
Due to the interaction between main oxidizer flow and the wall injected flow resulting from the regression process, a specific time characteristics identified in the frequency spectrum of streamwise velocity is generated in the hybrid rocket motor. In order to understand the response of the turbulent flow to two different types of external momentum forcing, LES analysis was conducted without considering the combustion. It turns out that both concentrated and distributed forcings do not lead to the disastrous resonance phenomenon. Energy contents are enhanced due to the added momentum but the peak frequency was not modified in the turbulent flow near the end of the rocket motor. Natural frequency of the flow system should be taken into account to further pursue the instability issue by using external forcing.

\section{초 록}

하이브리드 로켓 모터 내부에서는 산화제에 의한 주유동과 연료의 기화로 발생된 분출 유동이 상호작용을 하기 때문에 매우 강한 전단층이 발생되며 이에 기인한 시간특성이 나타나게 된다. 이 시간특성이 난류 유동장에 부과되면서 매우 복잡한 유동간섭 현상이 발생되게 되는데, 이와 같은 간섭현상이 외부교란에 대해 어떻게 반응하는지를 살펴보는 것은 안정적인 연소과정을 위해서 매우 중요하다. 이를 연구하기 위하여 연소반응을 제외 하고, 산화제의 난류 유동과 연료 벽면에서의 분출 유동을 모사한 채널 유동에 대한 LES 해석을 수행하였으며, momentum forcing기법을 사용하여 특정주파수를 부과하는 집중교 란(concentrated forcing)과 백색소음과 같은 넓은 범위의 주파수 특성을 부과하는 분산교 란(distributed forcing)에 대한 유동의 반응을 살펴보았다. 두 경우 모두 모터의 하류에서 외부교란의 특성시간을 유지하였으나 비약적인 유동의 공진현상으로 연결되지는 않는다 는 것을 확인하였다. 이는 외부교란의 특성은 시스템의 고유진동수 및 Kelvin-Helmholtz 불안정성에 기인한 특성 진동수와 함께 고려되어야 한다는 것을 의미한다.
\end{abstract}

Key Words : Hybrid rocket (하이브리드 로켓), Perturbations(외부교란), Natural frequency (특성진동수), Wall blowing(벽면 분출)

† 2009년 9월 15일 접수 2009년 12월 18일 심사완료

* 정회원, 건국대학교 기계공학과

** 정회원, 건국대학교 항공우주공학과 교신저자, E-mail : cjlee@konkuk.ac.kr

서울시 광진구 화양동 1 번지

\section{I. 서 론}

하이브리드 로켓은 개발비용이 상대적으로 낮으 며 지속적으로 안정한 운영이 가능하다는 장점이 있어 현재 많은 나라에서 각광을 받고 있다. 그 
러나 하이브리드 로켓의 연소는 고체 로켓의 예혼합 연소와는 다른 확산연소 특성을 갖고 있으 며 산화제가 매우 높은 속도로 연소실로 유입된 다. 따라서 연료 기화에 의한 벽면 분출유동과 산화제의 난류 유동 사이의 복잡한 상호간섭으로 인해 매우 복잡한 연소 과정이 발생하게 된다 [1-4].

하이브리드 로켓에 대한 기존의 연소 실험 결 과들을 살펴보면, 연소 후 연료 표면에 작고 불 균일한 셀 모양의 패턴이 형성되는 현상이 발생 된다는 것을 알 수 있는데, 관련 실험 결과들을 비교해보면, 비록 연소된 연료 표면의 거칠기 정 도에는 차이가 있지만 축방향을 따라 하류로 진 행해 감에 따라 거칠기의 정도가 점점 더 심해진 다는 것을 알 수 있다. 이와 같은 사실은 연료 및 산화제의 종류보다는 하이브리드 로켓 내부의 유동특성에 기인한 것으로 판단된다[3,5].

한편 하이브리드 로켓의 연소 과정에서는 불 규칙적인 연료 표면이 발생하는 현상 외에도 연 소 과정 중에 연소압력이 급격하게 상승하거나 또는 하강하는 DC-shift 연소 불안정 현상도 관 찰되고 있다[6-8]. 이 현상은 원래 고체추진 로켓 에서 관찰되는 대표적인 비선형 연소불안정 현상 으로 알려져 있다[9]. 고체 추진 로켓의 경우, 연 소율은 연소 압력에 비례하여 증가되는 특성이 있으나, 하이브리드 로켓의 연소율은 압력의 변 화와 무관하다고 알려져 있다. 그럼에도 불구하 고 하이브리드 로켓 연소에도 DC-shift 연소 불 안정이 나타난다는 사실은 두 종류의 로켓 연소 과정이 공통으로 갖는 역학적 특성이 존재한다는 것을 의미한다.

고체 로켓에서는 연료의 기화로 인해 발생되 는 질량이 추진제 앞부분에서 축적되기 시작하면 서 하류로 진행하는데, 이로 인해 발생된 유동은 층류 및 천이 상태를 거치면서 난류 유동으로 변 화해 간다. 이때 분출에 의하여 발생하는 축방향 유동 (injection-driven flow)은 하류방향의 분출 유동과 상호작용하면서 특정한 주파수 특성을 갖 는 유동으로 발전해 간다. 이와 같은 유동의 주 파수 특성은, 분출유동이 축-방향 유동과 상호작 용에 의하여 생성된 전단층 내에서 발생하는 와 흘림 (vortex shedding) 과 연관된 것으로 알려 져 있다[10,11].

반면 하이브리드 로켓의 경우, 난류 상태의 산 화제가 상대적으로 높은 속도(대략 30- $40 \mathrm{~m} / \mathrm{sec}$ ) 를 갖고 연소실로 유입되므로 고체 로켓의 유동 상태와는 다른 특성을 보이게 된다[12,13]. 따라 서 처음부터 난류 상태의 산화제 유동이 존재하
는 하이브리드 로켓의 연소에서, 연료 기화에 의 한 분출유동과 산화제 난류 유동이 일으키는 상 호 간섭이 어떤 역학적 특성을 나타낼 것인가를 살펴보는 것은 매우 흥미로운 일이다. 고체 로켓 의 경우에는 모터내부의 고유 주파수 특성을 갖 는 외부교란을 주었을 때, 연소실 내부에서 유동 이 층류에서 난류로 천이하는 특성 빨라지는 것 을 확인하였다[10-11]. 또한 외부교란에 기인한 공진이 발생하여 고체로켓 연소실 내의 유동장의 진동이 증가되는 것이 확인되었다. 이에 비하여 하이브리드 로켓의 경우, 연소실 내부에 난류상 태의 산화제가 이미 존재하기 때문에 외부 교란 이 주어졌을 때 고체 로켓의 경우와는 다른 반 응을 나타낼 것으로 예측할 수 있다[12-13].

따라서 본 연구에서는 연료 기화에 의한 분출 유동이 연소실로 유입된 산화제 난류유동과 상호 작용하는 과정에서 외부 교란을 가해졌을 경우 연료 표면 근처에서 유동의 진동 특성이 어떻게 변화하는지를 살펴보는 것을 목적으로 하고 있 다. 두 가지 다른 외부 교란이 고려되었는데, 집 중된 주파수로 교란을 중첩시키는 집중교란 (concentrated forcing)과 특정범위의 주파수대에 걸쳐서 교란을 부과하는 분산교란(distributed forcing)이 사용되었다. 선행 실험적 연구[3]에서 사용된 높은 Reynolds수 $(22,500)$ 의 유동을 효과 적으로 모사하기 위해서 LES 기법을 사용하였으 며, 계산에서 연소과정은 고려하지 않았다.

\section{II. 본 론}

\subsection{LES 방법론 및 유동 특성}

하이브리드 로켓 모터 내부에서는 산화제 공 급으로 발생된 주유동이 연료 벽면의 기화 과정 을 통해 발생된 유동과 서로 상호작용하기 때문 에 매우 복잡한 유동 현상이 발생된다. 먼저 고 체로켓 연소와는 달리 충분히 발달된 난류유동의 특성을 가진 산화제가 모터 내부로 유입되며, 혼 합 전단층에서 흔히 볼 수 있는 Kelvin -Helmholtz 타입의 유동 불안정성에 기인한 주 기적 시간 특성이 나타나며 또한 연료 벽면 근처 에서는 기화 과정에 영향을 받아 난류구조들이 기하학적으로 변형을 일으키게 된다. 이와 같이 매우 복잡한 난류유동 특성들이 동시에 존재하므 로 이들을 정확히 파악하기 위해서는 비정상 상 태(unsteady state)의 해석 기법이 필요하다. 본 연구에서는 난류유동의 특성을 제대로 해상하면 


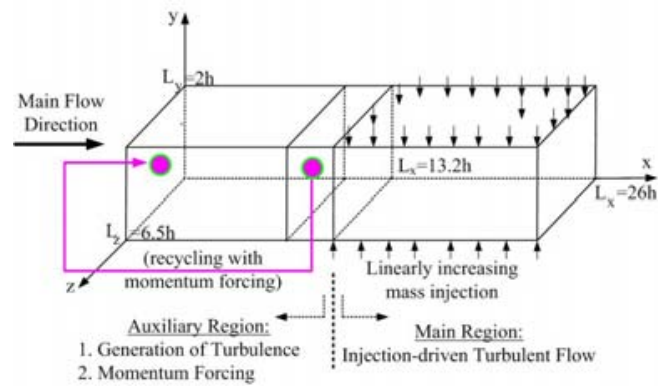

Fig. 1. 유동조건 및 계산 영역

서도 비정상 상태의 유동장 해석을 위하여 LES 기법을 채택하였으며, 자세한 방법론과 계산 영 역에 대한 정당성 등은 참고문헌 $[5,12,13]$ 에 설 명되어 있다.

Fig. 1은 본 계산에 사용된 유동 조건과 전산 해석을 위한 계산영역의 구성을 보여주고 있다. 여기서 길이는 채널 높이의 $1 / 2$ 인 $\mathrm{h}$ 로 표현되었 다. 계산영역의 입구에서 물리적으로 타당한 난 류 유동조건을 만들기 위하여 본 연구의 관심영 역 $(x>13 h)$ 의 앞부분에 단순채널을 임의로 위치시 키고 $(0<x<13 \mathrm{~h})$, 단순채널의 입구로부터 난류 특 성길이에 비해 충분히 멀리 떨어져 있는 위치 $(x=12.2 \mathrm{~h})$ 에서의 유동을 지속적으로 입구에 재순 환하도록 하였다. 이런 방법을 이용하여, 잘 발달 된 난류유동(fully-developed turbulent flow)이 본 연구의 주 관심영역인 벽면분출이 있는 계산 영역 $(x>13 h)$ 으로 공급되도록 하였다. 계산에 사 용된 레이놀즈 $(\operatorname{Re})$ 수는 실험조건[3]과 유사하도 록 22,500으로 하였으며, 격자계는 여러 번의 해 상도 점검 후, $1025 \times 193 \times 513$ 으로 결정되었다.

분출유동의 크기는 $x=13 \mathrm{~h}$ 의 위치에서 평균 산 화제 유동 속도의 $3 \%$ 로 주어졌으며, 이후 선형 적으로 증가하여 출구 $(x=26 h)$ 에서는 $5 \%$ 가 되도 록 하였는데 이 값은 최근에 보고된 실험결과들 을 $[3,4]$ 참조하여 결정하였다.

비압축성 유동을 가정한 LES계산을 위해서 필 터링된 연속방정식, Navier-Stokes방정식을 아래 와 같이 구성하였으며, 전산해석에 대한 방법론 은 참고문헌 $[5,12,13]$ 에 자세히 언급되어 있다.

$$
\begin{gathered}
\frac{\partial \overline{u_{i}}}{\partial x_{i}}=0 \\
\frac{\partial \overline{u_{i}}}{\partial t}=\frac{\partial}{\partial x_{j}}\left(\overline{u_{i}} \overline{u_{j}}\right)=-\frac{\partial \bar{p}}{\partial x_{i}}+\frac{\partial}{\partial} x_{j}\left(2 \nu \overline{S_{i j}}-\tau_{i j}\right)
\end{gathered}
$$

여기서 변수 위의 바(-)는 격자 필터링이 수행
된 변수를 나타내며, 잔류 응력(residual SGS stress) 텐서는 다음과 같이 정의된다.

$$
\tau_{i j}=\overline{u_{i} u_{j}}-\bar{u}_{i} \bar{u}_{j}
$$

$\mathrm{LES}$ 를 수행하는 경우, 잔류응력 텐서가 모델 링이 필요한 부분들이 된다. 동적혼성모델 (DMM)을 사용하는 경우, 먼저 잔류응력 텐서의 모델은 다음과 같이 두 가지 항으로 구성된다.

$$
\begin{gathered}
\tau_{i j}-\frac{\delta_{i j}}{3} \tau_{k k}=-2 \nu_{t} \overline{S_{i j}}+\left(L_{i j}^{m}-\frac{\delta_{i j}}{3} L_{k k k}^{m}\right) \\
\nu_{t}=C_{s} \overline{\Delta^{2}} \bar{S}
\end{gathered}
$$

식 (4)의 오른쪽 첫 번째 항은 모델링이 필요한 eddy viscosity를 포함하고 있으며, 두 번째 항은 해상된 유동장의 정보를 사용하여 외재적으로 직 접 계산해 낼 수 있는 수정된 Leonard 항이다.

Fig. 2와 3은 각각 음수값을 갖는 압력의 섭동 량 $\left(\mathrm{p}^{\prime}\right)$ 의 3차원 등고면과 난류구조들을 나타내 고 있다. 난류구조의 가시화를 위해서는 속도 텐 서의 eigenvalue를 사용한 검출기법[14]을 사용하 였다. Fig. 2는 분명히 Kelvin-Holmholtz 타입의 유동 불안정성이 발생되고 있다는 것을 보여주고 있다. 특히 음수 섭동값은 국부적으로 vortex 의 존재를 의미하므로 그림에서 보여지는 2-D roller 구조는 주유동과 벽면분출 유동의 상호 작용으로

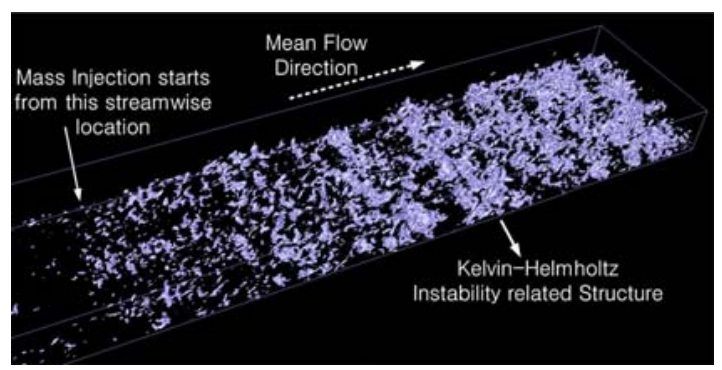

Fig. 2. 벽분사 영역에서의 음수값을 갖는 압력 섭돌량의 3차원 등고면

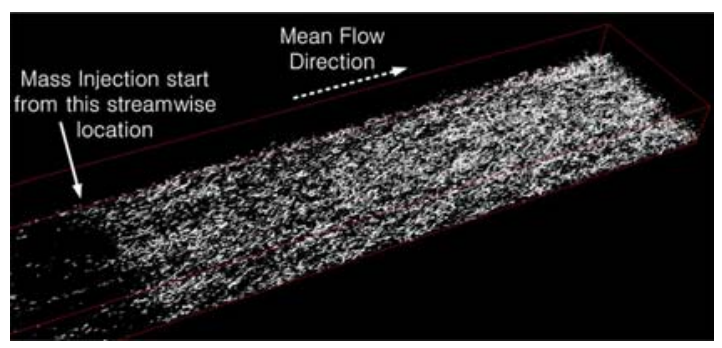

Fig. 3. 벽분사 영역에서의 난류구조 가시화 


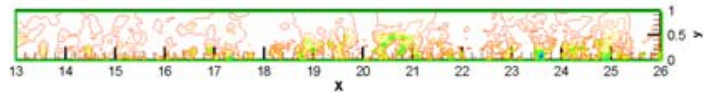

(a) 음수 압력 섭동량 $\left(p^{\prime}\right)$

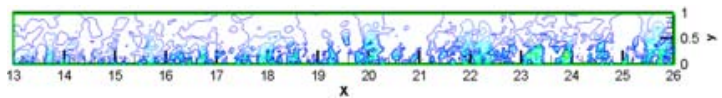

(b) 양수 압력 섭동량 $\left(\mathrm{p}^{\prime}\right)$

Fig. 4. 벽분사 영역에서 양수 압력섭동량 등고선

발생된 전단층의 불안정성과 관련되어 있다고 생 각된다. 그러나, vortex ID 기법[14]을 사용하여 검출한 난류구조는 벽면분출에 의해 전단층에서 매우 많은 난류구조가 생성된 것을 보여주고 있 으나, $\omega_{z}$ 성분의 vorticity로 표현되는 2-D roller 형상을 갖고 있지는 않다.

Fig. 4에서 압력 섭동량을 조금 더 자세히 살 펴보면 계산영역의 하류로 갈수록 양수-음수가 반복되는 패턴이 형성되고 있음을 알 수 있는데, 이와 같은 특성은 앞선 언급한 유동의 불안정성 에 기인한 것으로 배경 난류 유동장에 특성 시간 스케일을 부과하게 된다. 이와 같은 시간 특성은 주파수 스펙트럼에 더욱 명백하게 나타나게 되는 데, Fig. 5는 벽면 근처의 주유동방향 속도가 벽 면 분출에 의해 무차원화된 주파수 $\omega \approx 8.5$ 근처 에서 피크가 발생되는 것을 보여준다. 그림에 포 함되어 있는 첫 번째 위치인 $\mathrm{x} / \mathrm{h}=9.1$ 는 벽면분 사가 없는 지역에 속해 있으므로 $\omega \approx 8.5$ 의 특성 이 나타나지 않으며, 주파수가 증가함에 따라서 에너지량이 단조 감소하는 난류유동의 일반적인 특성이 나타난다. 그러나, 벽면분사가 시작되는 $x / h \approx 13$ 의 하류에서는 주파수 특성이 급격히 변화하게 되는데, 이는 여러 실험에서도 발견되 는 현상이다. Fig. 6과 7은 PMMA/GOX를 사용 한 실험에서 측정된 연소 압력변화와 시간 변화 에 따른 주파수 변화 특징을 보여주고 있다.

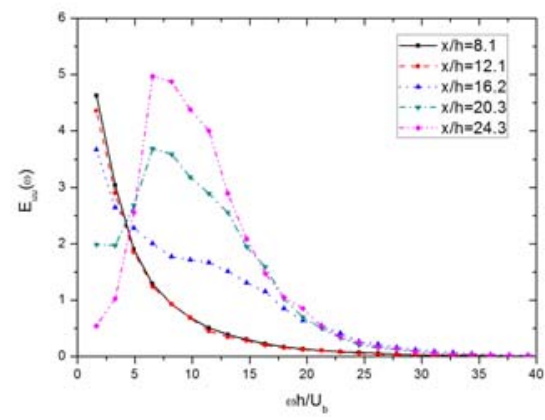

Fig. 5. 주유동방향 속도성분의 주파수 스펙트럼

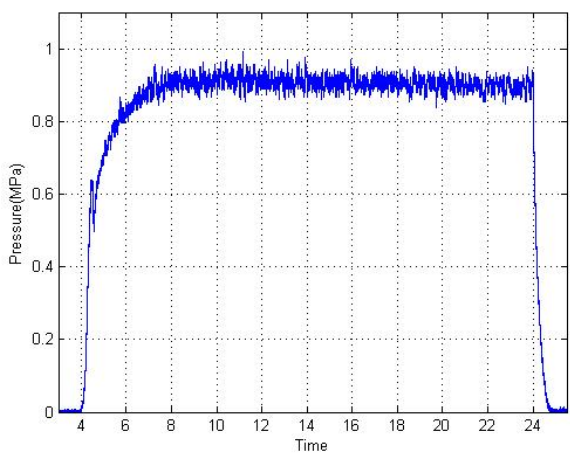

Fig. 6. PMMA/GOX 실험에서 연소압력

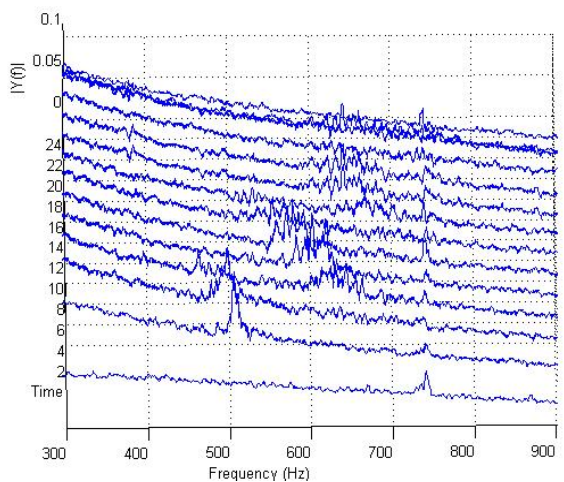

Fig. 7. 연소압력의 Frequency Water Fall

즉, 연소 초기에 $500 \mathrm{~Hz}$ 에서 시작된 주파수는 곧 사라지고 $630 \mathrm{~Hz}$ 부근의 주파수가 발견된다. 이 주파수는 시간이 지남에 따라 점점 변화하여 $520 \mathrm{~Hz}$ 부근까지 감소한다. 그 이후 다시 $650 \mathrm{~Hz}$ 부근의 주파수가 발생하여 연소 종료까지 이어진 다. 측정결과에 의하면 초기의 주파수 $520 \mathrm{~Hz}$ 는 예연소실과 연료 사이의 턱에 의하여 발생하는 vortex가 떨어져 나가면서 발생되는 주파수이며 $620 \mathrm{~Hz}$ 부근의 주파수는 하이브리드 산화제 유동 과 연소특성에 의한 주파수인 것으로 보인다.

하이브리드 모터 내부에서는 벽면분사 효과에 의해 산화제의 난류구조의 기하학적 구조가 크게 변화하게 되며 특성 시간 스케일이 발생되므로, 이와 같은 유동 특성의 변화가 물리적으로 연소 과정에 큰 영향을 미치게 된다. 실제 로켓 모터 의 운영 과정에서는 난류특성의 증가를 통해 유 동의 혼합특성을 개선하기 위한 다양한 장치 및 방안들이 사용되고 있으며 그와 같은 유동의 외 부인자들은 모터 내 유동에 외부 교란으로 작용 하게 된다. 예를 들어 산화제 주입부의 형상을 변경함으로써 발생되는 vortex는 형상의 기하학 
적 특성에 의존하는 시간 특성을 유동에 부과하 게 되는데, 이 경우 유동 특성이 어떻게 변화하 는지를 살펴보는 것은 매우 중요하다고 판단된 다. 본 연구에서는 수치적으로 두 가지 다른 특 성을 갖는 외부교란을 발생시키고 그들에 대한 유동의 반응을 살펴보고자 하였다. 선행 연구[13] 에서 언급된 바와 같이 외부교란의 증폭이 유동 의 소산성질에 의해서 제한되지 않는 상황이 된 다면 DC-Shift와 같은 현상을 발생시키게 될 것 이다. 앞서 언급한 바와 같이 난류 유동장에서 발생되는 유동의 불안정성 특성을 파악하는 것은 로켓 모터 내부의 연소과정을 이해하는데 매우 중요할 것으로 생각된다.

\section{2 외부교란 방법론}

로켓 모터 내부 유동에 직접적인 영향을 주는 외부교란은 다양한 형태로 발생될 수 있으나, 본 연구에서는 momentum forcing을 통한 교란을 고려하였다. Fig. 1에서 보여진 보조영역(auxiliary region)에서 특정 주파수 특성을 갖는 주유동방향 섭동량을 생성하여 이를 기본유동에 부과하였다. 이와 같은 외부교란 도입의 영향을 최소로 하면 서도 물리적으로 타당한 난류를 생성하기 위해서 momentum forcing은 보조영역(auxiliary region) 에 국한되었으며, 그 크기도 여러 차례의 기초 연구를 통해서 다음과 같이 결정하였다.

$$
\begin{gathered}
\left.u(y, z, t)\right|_{x=0}=\left.u(y, z, t)\right|_{\text {recycledplane }} \\
+\sum_{n} c_{n} a_{n}(y) \cos \left(\omega_{n} t\right)
\end{gathered}
$$

즉, 보조영역(auxiliary region)의 입구에 주기 특성을 갖는 외부교란을 생성한 후 이를 주유동 방향 속도에 더함으로써 momentum forcing을 시도하였다. 이를 위해 시간특성을 부여하기 위 한 기본함수 $\cos \left(\omega_{n} t\right)$, 벽면으로부터의 거리에 따라 변화되는 속도 섭동량을 고려하기 위한 함 수 $a_{n}(y)$, 그리고 외부교란의 크기를 조절하기 위한 계수 $c_{n}$ 을 조합하여 식(6)과 같은 외부교란 방법을 시도하였다. 앞서 언급한 바와 같이 계산 영역의 입구인 $x=0$ 의 위치에 인위적으로 생성 된 momentum forcing을 추가하였으므로, 보조 영역(auxiliary region)에서 물리적으로 타당한 난 류로 발달할 수 있도록 하였다.

\section{3 주파수 특성 분석}

\subsection{1 집 중교란(Concentrated Forcing)}

Fig. 5에서 보여진 것처럼, 벽면에서 발생되는 기화과정의 결과로 생성된 벽면분사는 산화제 주
유동과 서로 상호작용을 하면서 강력한 전단층을 형성하게 되며, 전단층의 불안정성에 기인한 시 간특성을 갖는 난류특성이 발생하게 된다. 대략 적으로 $w \approx 8.5$ 정도의 값을 갖는 것으로 나타나 므로, 외부교란도 같은 주파수 특성, 즉 $\omega_{n}=8.5$ 을 갖도록 하고 집중교란(concentrated forcing) 이에 대한 반응을 살펴보았다. 만일 유동장 내에 서 불안정성을 증폭시키는 역학적 작용이 불안정 성을 감소시키는 소산 작용보다 크다면 DC_Shift 와 같은 극한 상황이 발생될 수도 있을 것이며, 아니라면 외부교란의 크기에 의존하는 유동양상 이 발생하게 될 것이다. 유동의 반응은 외부교란 의 크기와 직접적으로 연관이 될 것이나, 본 연 구에서는 해당 $y$ 위치에서의 주유동방향속도 섭 동량의 $10 \%$ 정도의 교란을 부과하였다. 그보다 큰 교란은 보조영역(auxiliary region)에서 filtering된 Navier-Stokes 방정식을 만족하는 물 리적으로 타당한 난류를 발생시키는데 큰 어려움 을 부과하므로, momentum forcing을 통한 방법 론을 사용하면서 큰 교란을 생성하는 것은 타당 하지 않다고 판단하여 고려하지 않았다.

먼저 Fig. 8은 $\mathrm{x} / \mathrm{h}=9.1$ 의 위치에서 외부교란의 영향이 주유동방향 속도에 나타난 정도를 보여주 고 있다. 예상한 바와 같이 교란이 없는 경우 속 도는 다양한 범위의 주파수 특성을 갖게 되므로 특성 시간스케일이 두드러지게 나타나지 않는다. 그러나 집중교란(concentrated forcing)을 통해 $\omega_{n}=8.5$ 의 특성을 부과한 경우, 이 교란의 특성이 속도에 바로 나타나는 것을 볼 수 있다. 본 연구 에서는 momentum forcing을 통한 교란을 부과하 므로 속도성분은 거의 선형적인 반응을 보일 것으 로 예상된다. 압력장도 비슷한 경향을 보이는 것 을 Fig. 8에서 볼 수 있다. 주유동방향 속도 성분 과 마찬가지로 압력에도 외부교란에 포한된 $\omega_{n}=8.5$ 의 특성이 두드러지게 나타난다(Fig. 9).

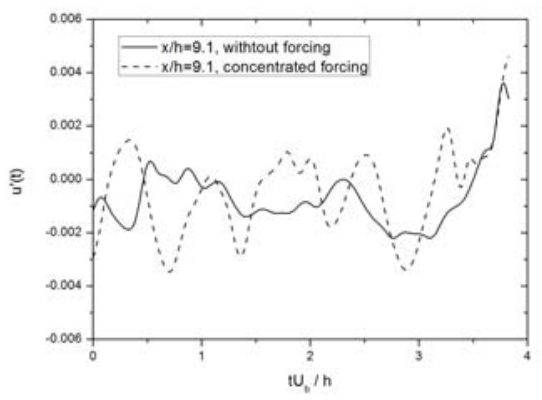

Fig. 8. 주유동방향속도 섭동량 히스토리. $\mathrm{x} / \mathrm{h}=9.1$ (concentrated forcing의 경우) 


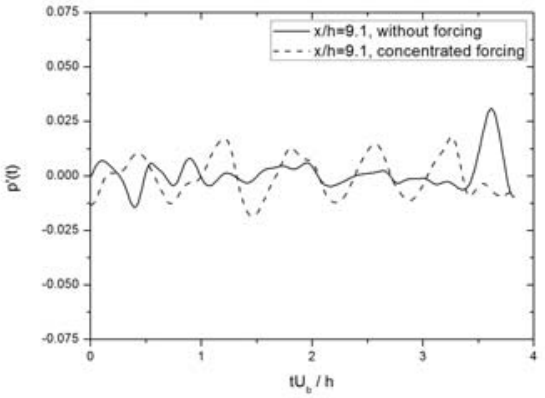

Fig. 9. 압력 섭동량 히스토리. $\mathrm{x} / \mathrm{h}=9.1$ (concentrated forcing의 경우)

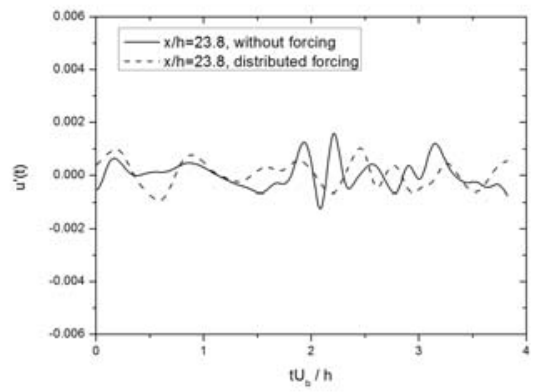

Fig. 10. 그림 7 주유동방향속도 섭동량 히스토리. $\mathrm{x} / \mathrm{h}=23.8$ (concentrated forcing의 경우)

따라서, 보조영역(auxiliary region)에서 target으 로 했던 시간특성이 난류유동장에 잘반영되었다 는 것을 알 수 있다.

위에서 기술한 외부교란이 벽면분사 영역을 거치면서 어떤 현상을 야기 시키는지를 알아보기 위해 먼저 주유동방향 속도 성분과 압력을 계산 영역의 뒤 부분인 $\mathrm{x} / \mathrm{h}=23.8$ 의 위치에서 시간의 함수로 검출해 보았다. 먼저, Fig. 10에서 보면 여전히 교란의 시간특성이 존재하는 것을 알 수 있으나 전반적인 난류에너지 양의 명백한 증가는 수반되진 않는다는 것을 알 수 있다. 그러나, 압 력의 경우에는 시간특성이 조금 더 확실하게 나 나타며 동시에 난류에너지의 증가도 같이 발생되 고 있다는 것을 알 수 있다(Fig. 11).

일반적인 압력장에서의 불안정성은 로켓 모터 의 안정적인 운영을 위협하는 직접적인 요소이므 로 이에 때한 특성을 조금 더 살펴보고자, 주파 수 스펙트럼을 살펴보았다. 본 연구에서 외부교 란을 식 (6)과 같이 momentum forcing을 형식을 통해서 제공하였으므로 외부 교란에 해당하는 난 류에너지량도 함께 공급한 것이 된다. 따라서, 주

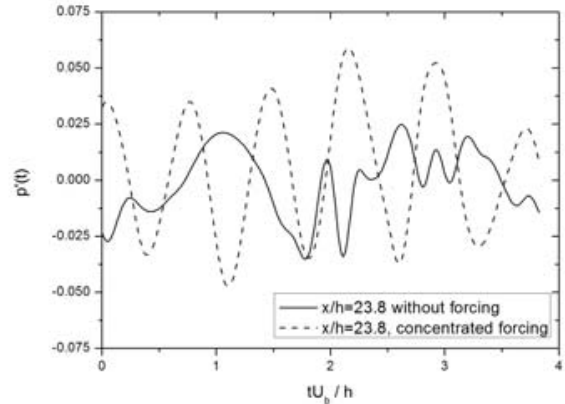

Fig. 11. 압력 섭동량 히스토리. $\mathrm{x} / \mathrm{h}=23.8$ (concentrated forcing의 경우)

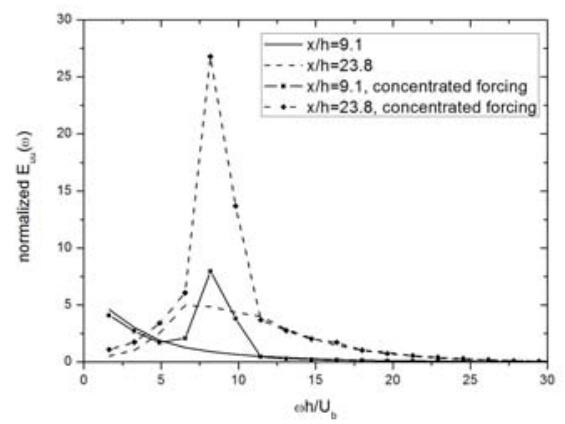

Fig. 12. 주유동방향속도성분의 주파수 비교 (concentrated forcing의 경우)

파수 스펙트럼의 공정한 비교를 위해서 스펙트럼 을 섭동량의 $\mathrm{rms}$ 값으로 무차원화 하였다.

Fig. 12는 주유동방향 속도 성분의 주파수 스 펙트럼을 두 개의 위치에서 비교한 것이다. 먼저, $\mathrm{x} / \mathrm{h}=9.1$ 의 위치에서는 momentum forcing에 의 한 에너지 증가가 발생되었고 또한 명백한 시간 특성이 나타나고 있다는 것을 알 수 있다. 하류 로 가면서도 이와 같은 경향이 지속적으로 유지 되고 있는 것을 알 수 있다. 즉, 외부로부터 $\omega_{n}=8.5$ 에 해당하는 시간스케일에 에너지가 공 급되었고 이 증대된 에너지가 계산영역 내에서는 소산되지 않고 계속 유지되는 것을 알 수 있다.

압력장 역시 매우 비슷한 경향을 보여주고 있 다는 것이 Fig. 13에 나타나 있다. 이는 Fig. 11의 결과와 일관된 양상이라고 할 수 있는데 즉, $\omega_{n}=8.5$ 에 해당하는 peak가 유지되고 해당 주 파수에서의 에너지가 증폭되었음을 알 수 있다. 앞서 언급한 바와 같이 에너지의 증폭 정도는 외 부교란량의 크기와 직접적으로 관련이 있을 것이 다. 교란량의 크기에 대한 영향을 아직 체계적으 로 분석해 보지는 않았으나, 식 (6)에서 $10 \%$ 정도 


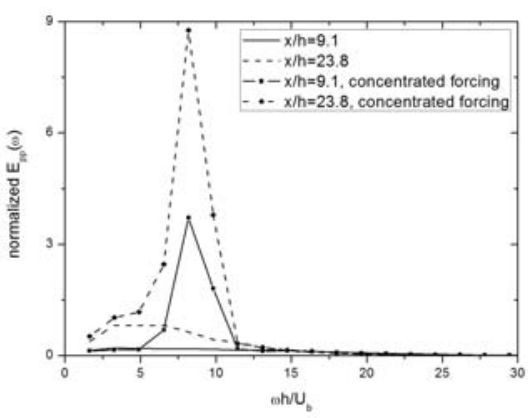

Fig. 13. 압력 주파수 비교 (concentrated forcing의 경우)

의 교란 $\left(c_{n}=0.1\right)$ 은 난류유동장에서 제공하는 소산에 의해 감소될 수 있는 범위를 벗어난 것으 로 생각된다. 비선형적인 과정을 통해 다른 주파 수로의 에너지 contents가 전달되어 나가는 현상 도 보이지 않는 것으로 보아, 난류구조의 비선형 동역학적 측면에서의 상호작용에 필요한 시간이 계산영역 크기의 제한으로 인해 충분히 제공되지 않았거나, momentum forcing의 물리적 제한점 과 관련이 있을 것으로 판단된다.

\subsection{2 분산교란(Distributed Forcing)}

실제 로켓 모터의 운영에는 여러 가지 이유로 인해 외부교란이 발생하게 된다. 앞서 다루었던 집중교란(concentrated forcing)의 경우는 특성 시 간 스케일 1 개를 외재적으로 부과하는 것이나, 백색소음 (white noise)과 같은 특성을 갖는 교란 을 시뮬레이션하기 위해서는 조금 더 다양한 시 간스케일을 동시에 부과하는 것이 타당하다. 본 연구에서는 식 (6)을 이용하여 $4 \leq \omega_{n} \leq 32$ 범위 에서 $c_{n}=0.02$ 의 값을 사용하여 분산교란 (distributed forcing)을 생성하여 유동장에 부과 하였다.

Fig. 14-15는 보조영역(auxiliary region)에서 생성된 분산교란(distributed forcing)이 주유동밯 향 속도와 압력에 반영된 양상을 보여주고 있다. 집중교란(concentrated forcing)의 경우와는 달리 단일 특성 시간 스케일이 두드러지게 나타나지 않는 것을 알 수 있는데 이는 본 연구의 목적에 적합한 교란이 생성되었음 의미한다. 이와 같은 특성을 갖는 난류신호가 주영역(main region)에 주입되면 벽면분사와 상호작용을 하게 되며, 이 결과 Fig. 16-17에서와 같은 반응을얻게 된다. 즉, $\mathrm{x} / \mathrm{h}=23.8$ 의 위치는 벽면분사에 의한 난류구조의 변화가 제일 명백하게 나타나는 곳임에도 불구하 고, 상류 $(\mathrm{x} / \mathrm{h}=9.1)$ 에서와 마찬가지로 명백한

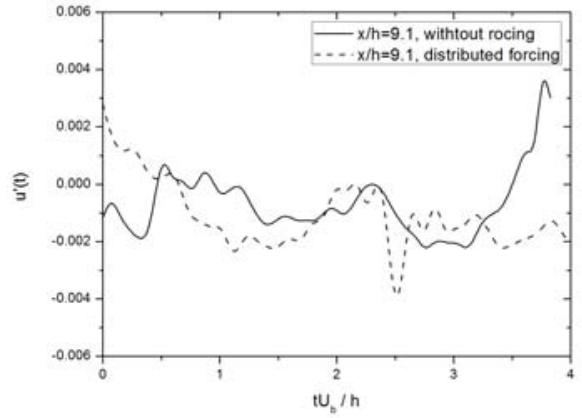

Fig. 14. 주유동방향속도 섭동량 히스토리. $\mathrm{x} / \mathrm{h}=9.1$ (distributed forcing의 경우)

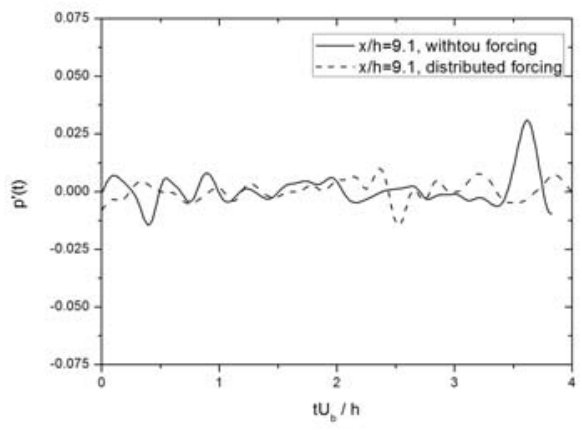

Fig. 15. 압력 섭동량 히스토리. $x / h=9.1$ (distributed forcing의 경우)

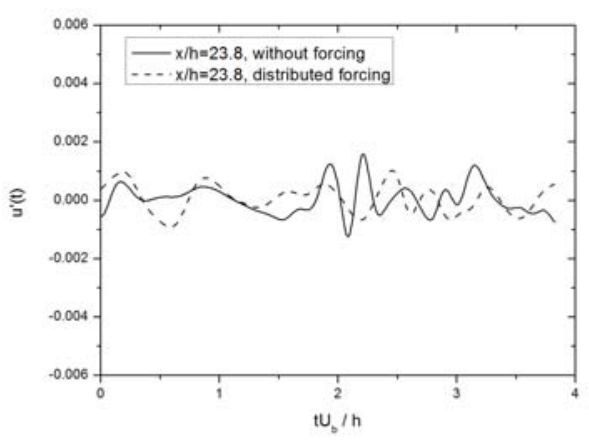

Fig. 16. 그림 7 주유동방향속도 섭동량 히스토리. $\mathrm{x} / \mathrm{h}=23.8$ (distributed for3cing의 경우)

단일 시간특성의 발현을 발견되지 않았다.

분산교란(distributed forcing)의 역할을 살펴보 기 위해 주유동방향 속도와 압력의 주파수 특성 을 살펴보았다. Fig. 18는 외부 분산교란의 영향 이 매우 제한적이라는 것을 보여주고 있다. 특히 $4 \leq \omega_{n} \leq 32$ 범위에서 교란을 발생시켰으므로 이 영역에서만 에너지 content가 약간 증가되었 을 뿐 명백한 공진현상은 발견되지 않았다. 이 


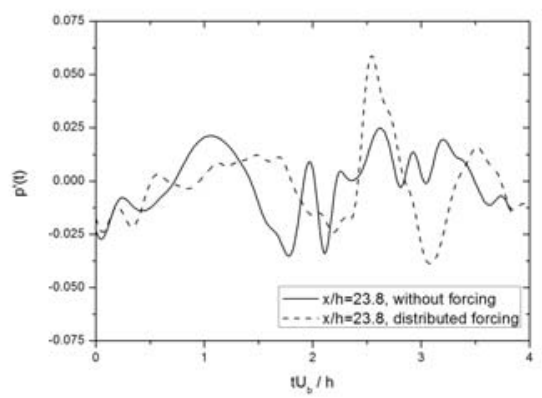

Fig. 17. 압력 섭동량 히스토리. $x / h=23.8$ (distributed forcing의 경우)

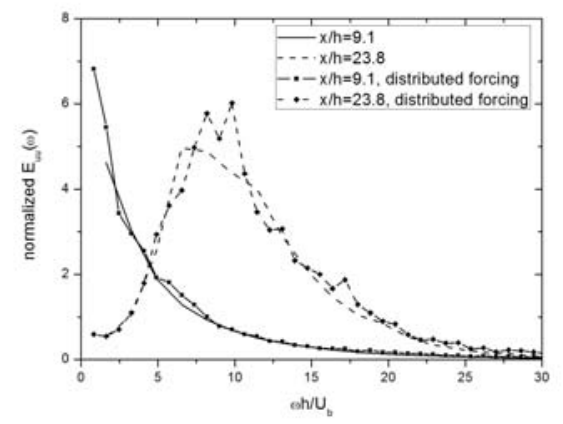

Fig. 18. 주유동방향속도성분의 주파수 비교 (distributed forcing의 경우)

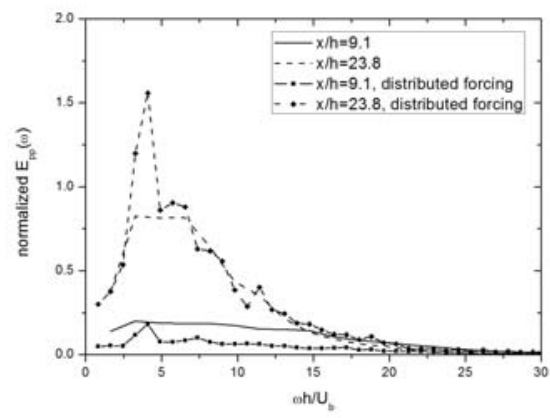

Fig. 19 .압력 주파수 비교 (distributed forcing의 경우)

역시 $c_{n}$ 값이 크지 않았다는 사실과 관련이 있을 것으로 생각되나, $\omega=8.5$ 의 특성을 제외한 배경 유동장이 갖는 고유 불안정성 관련 시간 특성이 $4 \leq \omega_{n} \leq 32$ 의 영역에는 존재하지 않을 수도 있 다는 것을 의미한다.

압력장은 조금 다른 양상을 보여주는데, Fig. 19 에서와 같이 압력장은 주유동방향속도 성분에 비해서는 증폭의 정도가 상대적으로 크다는 것을 알 수 있다. 본 계산이 대략 $1025 \times 193 \times 513$ 즉
$101 \times 10^{6}$ 의 격자계를 사용하는 방대한 해석이므 로 계산비용을 고려하여 다양한 $c_{n}$ 의 영향을 살 펴보지는 못했다. 그러나, 몇몇의 실험결과에서 알려진 바와 같이 백색소음이 하이브리드 모터 내부에서 불안정성의 증대를 야기 시키지 못한다 는 결과를 볼 때, 분산교란(distributed forcing)으 로는 DC-Shift와 같은 현상에 도달할 수 없을 것 이라고 판단된다. 물론 정확한 결론을 위해서는 조금 더 다양한 형태의 교란을 유동에 부과한 후 그 반응을 살펴보아야 할 것이나 이에는 매우 방 대한 계산자원이 필요할 것이므로 매우 다양한 데이터를 제공하는 것은 쉽지 않을 것이나 지속 적으로 추구될 것이다.

\section{III. 결 론}

하이브리드 로켓 연소에서는 난류특성을 갖는 산화제 유동과 연료의 기화로 인한 분출유동이 상호 작용을 하게 되는데, 그 결과로 형성된 유 동장에 부과된 외부교란의 영향을 살펴보기 위해 서 연소반응을 제외한 LES 해석을 채널의 형상 에서 진행하였다.

산화제 난류 유동과 벽면 분출 유동은 상호작 용을 하며 혼합 전단층의 불안정성을 만들어내게 되는데, 고체추진 로켓의 연소과정에서 관찰되는 것과 비슷한 특정주파수 $(\omega=8.5)$ 로 진동하고 있 는 유동양상을 발생시킨다. 외부교란에 의해서 이 현상이 어떻게 변화하는 지를 파악하기 위해 서 두 가지 다른 종류의 외부교란을 부과한 후 난류 특성을 검출하였다. 집중교란(concentrated forcing)을 통해 기본 유동장이 갖고 있는 특성 주파수와 동일한 시간특성을 부과하게 되면 난류 유동장이 선형적인 반응을 보이게 되는데, 외부 교란에 기인한 에너지 content가 증가하나 동일 한 시간특성이 유동장에서 계속 유지되는 것을 확인하였다. 분산교란(distributed forcing)의 경 우, 단일 시간 특성이 아닌 분산된 시간 특성을 갖는 교란을 $4 \leq \omega_{n} \leq 32$ 범위에서 생성하여 유 동장에 부과하였는데 이 경우 역시 위 범위를 벗 어난 지역에 미치는 영향이 미비하였다.

실제 하이브리드 모터의 작동에서 발생할 수 있는 다양한 외부교란 요인 중에서 기하학적 특 성에 의한 경우는 집중교란(concentrated forcing) 과 유사하다고 볼 수 있으며, 각종 진동 및 소음 등에 의한 경우는 분산교란(distributed forcing) 으로 표현될 수 있는데, 본 연구에서는 두 경우 모두 DC-shift와 같은 불안정성의 급격한 증가와 
는 연결되지 않았다. 외부교란 방법의 한계에 의 한 것인지, 시스템이 갖는 고유진동수 값과의 상 당한 차이로 인한 것인지 확실하지는 않지만, 시 스템 고유진동수의 파악, Kelvin- Helmhotz 불안 정성에 의한 특성 그리고 외부교란의 상관관계를 정확히 이해하기 위한 더욱 많은 연구가 필요할 것으로 생각된다.

\section{후 기}

본 연구는 한국연구재단의 2008년도 기초연구 과제사업으로 지원된 연구이며 두 번째 저자는 지원해주신 한국연구재단에 감사드립니다.

\section{참고문헌}

1) C. Lee, Y. Na, Y. Hwang, and S. Lee, Turbulent flow in the helical grain of hybrid rocket fuel, AIAA-2006-4344, 41st AIAA Joint propulsion meeting, Sacramento, Ca., 2006.

2) B. Evans, Nicholas A. Favorito, and K. K. Kuo. "Oxidizer-Type and Aluminum-Particle Addition Effects on Soild-Fuel Burning Behavior", AIAA paper 06-4676, 42nd AIAA/ASME/SAE/ASEE Joint Propulsion Conference \& Exhibit, 2006.

3) 구원모, 이창진, 산화제 난류 유동 변화에 대한 하이브리드 로켓 연소 특성, 한국추진공학 회 춘계학술대회 논문, 2007.

4) K.H Shin, C. Lee, S. Y. Chang, and J. Y. Koo, "The enhancement of regression rate of hybrid rocket fuel by various method", AIAA 2005-0359, 2005.

5) C. Lee and Y. Na, "Large Eddy Simulation of Flow Development with Surface Mass Injection", J. Propulsion and Power, Vol. 25, No. 1, pp. 51-59, 2009.
6) J. P. Avres and H. S. Jones, "Explanation of DC-shift in Hybrid Rocket Motor", AIAA Paper 1997-2938, 1997.

7) Boardmann T. A., Carpenter, R. L. and Clafin, S. E., A Comparative Study of the Effect of Liquid versus Gaseous Oxygen Injection on Combustion Stability in 11 inch Diameter Hybrid Motors, AIAA Paper 1997-2936, 1997.

8) J. P. Avres and H. S. Jones, "Elimination of DC-shift in Hybrid Motors", AIAA Paper 1997-2939, 1997.

9) M. A. Karabeyoglu "Thermal Transients in Hybrid Rockets Fuel Grains-Non-Linear Effects" AIAA paper 07-5369, Cincinnati, OH, 2007.

10) G. Avalon, G. Casalis, and J. Griffond, "Flow Instabilities and Acoustic resonance of channels with wall injection", AIAA paper 98-3218, Cleveland, OH, 1998.

11) S. V. Apte, and V. Yang, A large eddy simulation study of transition and flow instability in a porous-walled chamber with mass injection, J. Fluid Mechanics, Vol. 477, pp. 215-225, 2003.

12) 나양, 이창진, 분출유동이 있는 채널 난류 유동의 LES 해석, 항공우주학회지, 제 35 권 제8호, pp. 699-705, 2007.

13) 나양, 이창진, 채널유동에서 질량분사에 의 한 표면유동의 진동 특성, 항공우주학회지, 제 37 권 제1호, pp. 62-68, 2009.

14) J. Zhou, C. D. Meinhart, S. Balachandra and R. J. Adrian, "Formation of Coherent Packets in Wall Turbulence", Self-Sustaining Mechani는 of Wall Turbulence, edited by R. L. Panton, Computational Mechanics Publications, Boston, MA, pp. 109-134, 1997. 